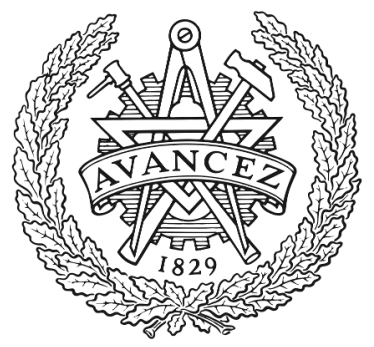

CHALMERS

UNIVERSITY OF TECHNOLOGY

\title{
Barriers and opportunities in bio-based production of hydrocarbons
}

Downloaded from: https://research.chalmers.se, 2023-04-26 13:47 UTC

Citation for the original published paper (version of record):

Zhou, Y., Kerkhoven, E., Nielsen, J. (2018). Barriers and opportunities in bio-based production of hydrocarbons. Nature Energy, 3(11): 925-935. http://dx.doi.org/10.1038/s41560-018-0197-x

N.B. When citing this work, cite the original published paper. 


\title{
Barriers and opportunities in bio-based production of hydrocarbons
}

\author{
Yongjin J. Zhou $\circledast^{1,2,3}$, Eduard J. Kerkhoven $\oplus^{3}$ and Jens Nielsen ${ }^{3,4,5 \star}$
}

\begin{abstract}
Global climate change caused by the accumulation of greenhouse gases (GHGs) has caused concerns regarding the continued reliance on fossil fuels as our primary energy source. Hydrocarbons produced from biomass using microbial fermentation processes can serve as high-quality liquid transportation fuels and may contribute to a reduction in GHG emissions. Here, we discuss the barriers and opportunities for bio-based production of hydrocarbons to be used as diesel and jet fuels and review recent advances in engineering microbes for production of these chemicals. There are two main challenges associated with establishing bio-based hydrocarbon production from cheap feedstocks; lowering the cost of developing efficient and robust microbial cell factories and establishing more efficient routes for biomass hydrolysis to sugars for fermentation. We discuss how to develop novel systems and synthetic biology tools that can enable faster and cheaper construction of microbial cell factories and thereby address the first challenge, as well as recent advances in biomass processing that will likely lead to overcoming the second challenge in the near future.
\end{abstract}

\section{T} he transport sector accounts for one of the largest and fastestgrowing consumers of energy, and is one of the most difficult to decarbonize. For example, in the United States about $30 \%$ of energy usage is spent on transportation, which currently mainly relies on liquid fuels ${ }^{1}$. Even though there are projections of a rapid increase in electric cars, high-power transport vehicles (airplanes, ships and long-haul trucks) need high energy-density fuels (including high-capacity energy storage, fast energy release and rapid charge), and current alternative energy storages (mainly batteries) cannot meet this requirement ${ }^{2}$. A failure to displace the fossil fuels used in these heavy vehicles with alternatives would result in emissions exceeding the $2{ }^{\circ} \mathrm{C} \mathrm{COP} 21$ target $^{3}$. Even though it today only accounts for about 3\% of GHG emissions, flight-travels emission is expected to increase dramatically in the coming years ${ }^{4}$. Furthermore, besides reducing net GHG emissions, bio-based jet fuels can be less detrimental to air quality than traditional jet fuel; it has been demonstrated that when camelina oil-derived biofuel is blended 50:50 (by volume) into traditional jet fuel, particle and mass emissions are reduced by $50-70 \%$.

Currently, biodiesel and bio-kerosene are produced from vegetable oils, but this production is problematic since it competes against use of these oils in the food sector. Furthermore, the yield of oil per hectare is very low compared with that of sugar cane, other sugar crops and biomass. Thus, the production of bioethanol from sugar cane yields 5,000 $1 \mathrm{ha}^{-1}$ and 1,000-3,000 $\mathrm{l} \mathrm{ha}^{-1}$ from corn, whereas production of biodiesel from soybean only yields about $5001 \mathrm{ha}^{-1}$ (calculated based on the information from ref. ${ }^{6}$ ). Even though processes have been developed for dehydrogenation and cracking of non-food plant oils, referred to as hydrogenated esters and fatty acids (HEFA) processes, for example, by AltAir Fuels in California who is supplying biofuels to United Airlines, these processes will suffer from relatively low crop yield. There is therefore a need for developing cell factories that can produce hydrocarbons $s^{7,8}$ to be used as diesel fuels, as this will allow the use of both conventional feedstocks such as corn and sugar cane as well as biomass.

Due to its ease of production and easy blend into gasoline, ethanol serves as a good biofuel, but its lower energy content and hygroscopicity limits its wider application. Petroleum-derived liquid transportation fuels are hydrocarbons with chain lengths of C5 to $\mathrm{C} 20$ and they posses energy density around $40 \mathrm{MJ} \mathrm{kg}^{-1}$. Among these, jet fuels contain aromatic compounds along with linear, branched and cyclic paraffins with a chain length of C8-C16, which ensure the specific lubricity, freezing point and energy density that keep it from boiling, freezing or absorbing water in various conditions on land or in the air?. Thus, making similar molecular components is necessary for use in the current airline infrastructure. Current biofuels contain only linear and branched paraffins and thus have to be blended with petroleum-derived fuels to ensure appropriate properties. For high-level production of hydrocarbons, Gevo developed a process for conversion of isobutanol to hydrocarbons through condensing its dehydration intermediate isobutene ${ }^{10}$. However, cost-wise it is more attractive to have a direct production of hydrocarbons in the bioprocess, and techno-economic analysis has shown that even though the mass yield of hydrocarbons from glucose is lower than for ethanol, the energy yield can be almost the same ${ }^{11}$. Furthermore, production of hydrocarbons directly by fermentation has a better net energy balance than production of ethanol ${ }^{11}$. Projections made by the International Energy Agency also state that the total biofuel demand will exceed 30 EJ by 2050 and that biofuels to be used for trucks and jets may account for more than $50 \%$ of this ${ }^{12}$. We will therefore likely see expanded biorefineries in the future, where plant biomass or natural gas is converted to hydrocarbons by microbial cell factories, and thereby provide clean and $\mathrm{CO}_{2}$-neutral diesel fuels (Fig. 1).

In this Review, we examine how to address the two major barriers in establishing bioprocesses for hydrocarbon production.

\footnotetext{
'Key Laboratory of Separation Science for Analytical Chemistry, Dalian Institute of Chemical Physics, Chinese Academy of Sciences, Dalian, China. ${ }^{2}$ Division of Biotechnology, Dalian Institute of Chemical Physics, Chinese Academy of Sciences, Dalian, China. ${ }^{3}$ Department of Biology and Biological Engineering, Chalmers University of Technology, Gothenburg, Sweden. ${ }^{4}$ Novo Nordisk Foundation Center for Biosustainability, Technical University of Denmark, Lyngby, Denmark. ${ }^{5}$ Beijing Advanced Innovation Center for Soft Matter Science, Beijing University of Chemical Technology, Beijing, China. *e-mail: nielsenj@chalmers.se
} 


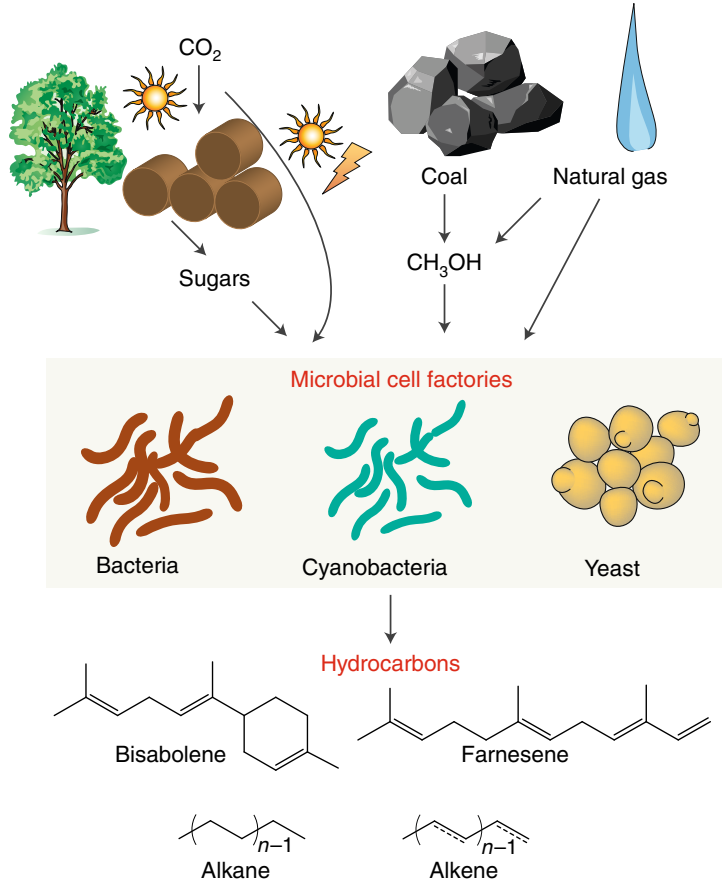

Fig. 1 | The biorefinery concept for biofuel production from sunlight and single-carbon compounds or biomass. Exploiting biological processes for production of hydrocarbons by using either biomass produced from $\mathrm{CO}_{2}$ or direct use of $\mathrm{CO}_{2}$ or $\mathrm{CH}_{4}$. Biomass is synthesized from $\mathrm{CO}_{2}$ and solar energy (sunlight) via photosynthesis, and then physical and chemical pre-treatment is used to generate 5-and 6-carbon sugars, which can subsequently be converted into hydrocarbons by microbial fermentations using engineered microbial cell factories. $\mathrm{CO}_{2}$ can also be directly condensed to hydrocarbons using an integrated energy supplying module (for example, solar energy and electricity) by engineered microbial cell factories. Furthermore, microbes can be harnessed for biotransformation of other single-carbon molecules such as methanol and methane, which can be derived from coal, natural gas and so on.

First, the efficiency of cell factories producing hydrocarbons has to be improved significantly. Current yields that are obtained in academic laboratories are typically much lower than the theoretical maximum yield ${ }^{11}$. It is challenging to engineer the metabolism of microorganisms and it has been estimated to cost in the range of US\$50-100 million just to develop the cell factory for a novel bioprocess ${ }^{13}$, and this represents a major barrier for development of novel bioprocesses, particularly in the current regime of relatively low oil prices. However, as discussed here developments in synthetic biology and systems biology are increasing our knowledge of biosynthetic pathways leading to hydrocarbons and how we can rapidly engineer cell factories to become more efficient. Second, even though biodiesel and bio-kerosene can be produced from corn and sugarcane, it is necessary to establish biomass-based processes to ensure sufficient provision of these fuels. Even though there has been much research and development towards implementing second-generation bioethanol production, that is, ethanol production from biomass, it is still challenging to integrate microbial fermentation processes with biomass hydrolysis processes. We will, however, briefly discuss that recent developments suggest that solutions to this challenge are likely to be identified within the coming years. Finally, we also discuss how alternative single-carbon feedstocks and chemical-biological hybrid processes can be explored for hydrocarbon production.
Microbial metabolic pathways for hydrocarbon biosynthesis Hydrocarbon biosynthesis from oxygen-rich sugars present in corn, sugar cane and biomass requires extensive chemical reduction, and there are three naturally evolved reduction extension cycles for production of naturally occurring hydrocarbons ${ }^{2}$ : biosynthetic pathways of isoprenoids, fatty acids and polyketides. These all rely on acetyl coenzyme A (acetyl-CoA) as a precursor, which therefore is a central metabolite for biosynthesis of hydrocarbons (Fig. 2 and Table 1).

Hydrocarbon production from the isoprenoid pathway. Isoprenoids are naturally produced metabolites with diverse structures and functions that have wide applications as medicines, fragrances and flavours, but some isoprenoids are also very well suited as fuels. Isoprenoids are synthesized by condensing five carbon units with dimethylallyl diphosphate (DMAPP) as primer and isopentenyl diphosphate (IPP) as extending units, which are generated via the D-xylulose-5-phosphate (DXP) pathway or the mevalonate (MVA) pathway (Fig. 2).

The shortest isoprenoid, isoprene (C5), is an important commodity chemical used in a wide range of industrial applications, including as a gasoline alternative. Genencor has developed a gas-phase bioprocess for isoprene production of $60 \mathrm{~g} \mathrm{l}^{-1}$ by engineering the endogenous DXP and heterologous MVA pathways in Escherichia coli (E. coli), resulting in a volumetric productivity of $2 \mathrm{~g} \mathrm{l}^{-1} \mathrm{~h}^{-1}$ and a yield of $11 \%$ isoprene from glucose $\mathrm{e}^{14}$. Other microbes, such as yeast and cyanobacteria, were also explored for isoprene production with much lower titre ${ }^{15,16}$. Cyanobacteria-based terpene production would provide a direct route for fixing of $\mathrm{CO}_{2}$ and solar energy by photosynthesis ${ }^{16,17}$.

Monoterpenes (C10) are considered good candidates for jet fuel and biodiesel, since they have desirable properties such as low freezing temperature and high ignition stability. Monoterpenes are synthesized from geranyl pyrophosphate (GPP) by diverse monoterpene synthases. GPP is synthesized by the GPP synthase (GPPS), which condenses IPP and DMAPP. E. coli has been extensively explored as a cell factory for production of monoterpenes such as limonene and sabiene ${ }^{18}$. With engineering of isoprenoid pathways and monoterpene synthase, diverse monoterpenes such as limonene and pinene were overproduced at $0.6-3 \mathrm{~g} \mathrm{l}^{-1}$ (Table 1) $)^{19-21}$. Yeasts have also been extensively engineered for monoterpene production; however, the production is much lower (about $0.02 \mathrm{~g} \mathrm{l}^{-1}$ ) than by $E$. $\operatorname{coli}^{22,23}$. The lower production might be attributed to low availability of precursor GPP, since the yeast GPP synthase Erg20 is a bi-functional enzyme with a higher farnesyl pyrophosphate synthase (FPPS) activity consuming GPP, and mutation of Erg20 enzyme with decreased FPPS activity enabled a 340-fold improvement of sabinene production compared with the original enzyme in Saccharomyces cerevisiae (S. cerevisiae $)^{23}$.

Sesquiterpenes $(\mathrm{C} 15)$ are another class of molecule of which several have excellent properties as biofuels. Amyris, an industrial biotechnology company, has developed a yeast cell factory for the production of farnesene ${ }^{24}$, taking advantage of its experience with successful engineering of yeast for commercial production of artemisinin, an anti-malarial drug. Besides extensive engineering of the MVA pathway that is required for artemisinin production ${ }^{25}$, the supply of the precursor acetyl-CoA was improved by constructing alternative acetyl-CoA pathways with reduced adenosine triphosphate (ATP) consumption, reduced $\mathrm{CO}_{2}$ emission and improved redox balance ${ }^{24}$. Furthermore, an nicotinamide adenine dinucleotide (NADH)-consuming 3-hydroxy-3-methyl-glutaryl (HMG)-CoA reductase (NADH-HMGR) was introduced to replace the NADPH dependent HMGR, which improved the overall cofactor balance. The engineered strain with this rewired central metabolism had a $25 \%$ higher farnesene yield from glucose $\left(130 \mathrm{~g} \mathrm{l}^{-1}, 0.173 \mathrm{~g}\right.$ per $\mathrm{g}$ glucose) and $75 \%$ less oxygen requirement, which could reduce 


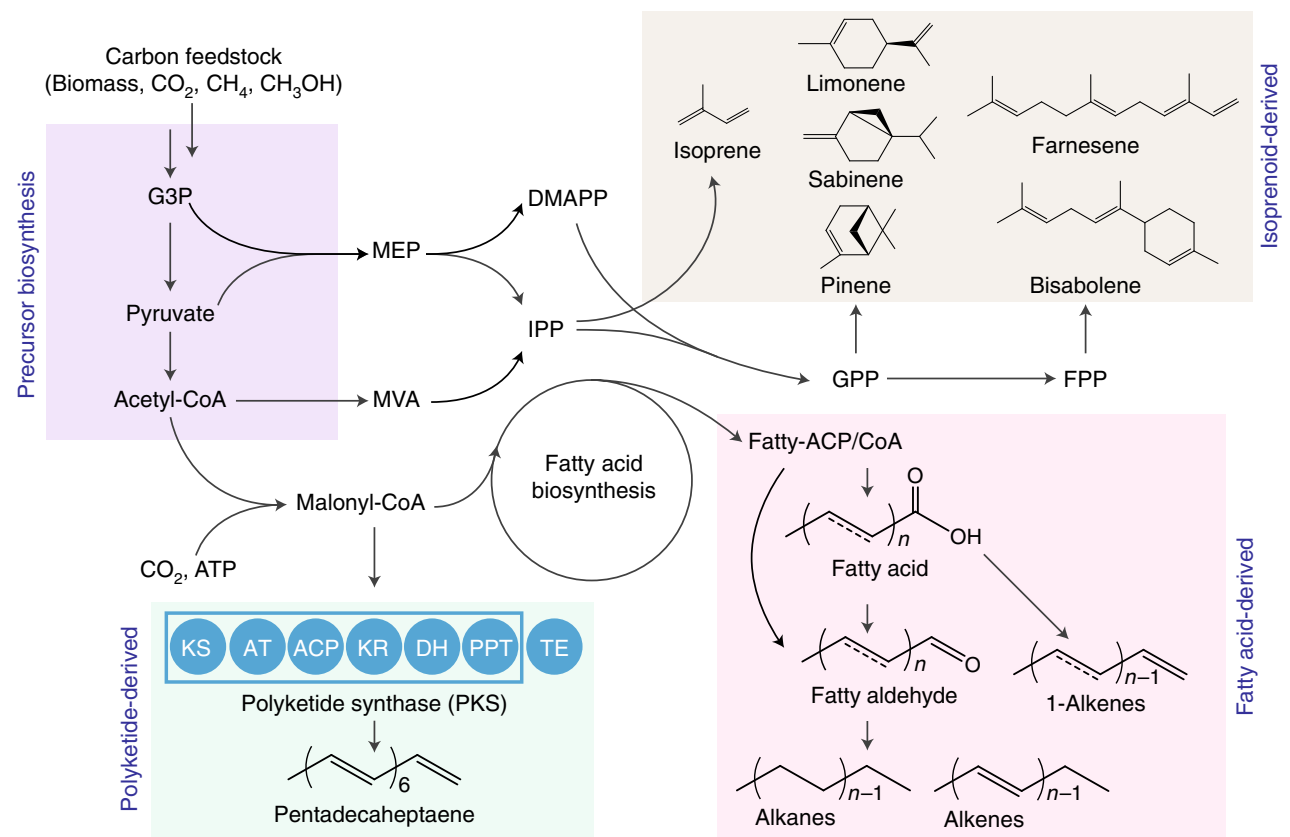

Fig. 2 | Metabolic pathways for production of hydrocarbons in microorganisms. Single-carbon feedstocks are condensed to the common precursors pyruvate or acetyl-CoA while biomass derived sugars are catabolized to precursors in central metabolism, and the precursors are used as building blocks for biosynthesis of chain-extended intermediates by isoprenoid, fatty acid or polyketide biosynthetic pathways. Downstream tailored pathways transform intermediates to hydrocarbons that can be used directly as drop-in biofuels. G3P, glyceraldehyde 3-phosphate; MEP, methylerythritol 4-phosphate; MVA, mevalonate; DMAPP, dimethylallyl diphosphate; IPP, isopentenyl diphosphate; GPP, geranyl diphosphate; FPP, farnesyl diphosphate. The polyketide synthase contains multiple domains (shown in a box): KS, $\boldsymbol{\beta}$-keto-synthase; AT, acyl-transferase; ACP, acyl carrier protein; KR, $\boldsymbol{\beta}$-keto-reductase; $\mathrm{DH}$, dehydratase; PPT, phosphopantetheinyl transferase. TE, a cognate thioesterase that is separately expressed.

the raw material and operational costs. Bisabolane, a fully reduced derivative of the sesquiterpene bisabolene, has been shown to be a good D2 diesel alternative in terms of physical and chemical properties. E. coli and S. cerevisiae were engineered for production of bisabolene by selecting the efficient bisabolene synthases and engineering the upstream isoprenoid pathway ${ }^{26}$, which enabled production of $900 \mathrm{mg} \mathrm{l}^{-1}$ bisabolene. This study also showed that $20 \%(\mathrm{v} / \mathrm{v})$ bisabolene had no negative effect on growth, which indicated that bisabolene has limited toxicity to E. coli and S. cerevisiae, enabling further improvement.

Hydrocarbon production from fatty acid biosynthetic pathway. Fatty acids are obvious precursors for production of alkanes and alkenes ${ }^{27}$. Fatty acids are biosynthesized by fatty-acid synthase (FAS) using acetyl-CoA and malonyl-CoA as building blocks (Fig. 2). The products of fatty acid synthase are acyl-acyl carrier protein (ACP)/CoA or free fatty acids (FFAs), which can be converted to hydrocarbons via two different pathways (Fig. 2): two-step alkane biosynthesis where alkanes are synthesized from free or activated fatty acids through reduction to fatty aldehydes followed by conversion to alkanes by aldehyde-deformylating oxygenases (ADOs) ${ }^{28,29}$; and one-step 1-alkene biosynthesis directly from free fatty acids by different enzymes ${ }^{30-33}$.

Though some cyanobacteria naturally produce low levels of long-chain alkanes, their biosynthetic pathway was only recently elucidated ${ }^{28}$. The reconstruction of the alkane biosynthetic pathway from cyanobacteria in $E$. coli enabled the production of alkanes at $0.3 \mathrm{~g} \mathrm{l}^{-1}$, which were mainly mixtures of C13, C15 and C17 (ref. ${ }^{28}$ ). To obtain gasoline-like alkanes, the $E$. coli fatty acid metabolism was engineered for short-chain fatty acid production followed by reconstruction of an alkane pathway, which enabled the production of short-chain alkanes at $580 \mathrm{mg} \mathrm{l}^{-1}$ (ref. ${ }^{34}$ ). E. coli has also been engineered for production of propane at $32 \mathrm{mg} \mathrm{l}^{-1}$ by manipulating fatty acid synthesis for supply of the precursor butyrate ${ }^{35}$. Recently, modular engineering of the $\beta$-oxidation operating in a reverse direction enabled the biosynthesis of short-chain alkanes (propane, butane and pentane $)^{36}$.

The low alkane biosynthesis in microbes is mainly attributed to poor catalytic activity of $\mathrm{ADOs}^{37}$ and strong competition of aldehyde reductases and alcohol dehydrogenases (ALR/ADHs) ${ }^{38}$. To increase the ADO activity and relieve ALR/ADH competition, protein fusion and scaffolding were applied to improve the channelling of substrate fatty aldehyde between AAR and ADO, which enabled two to eight times higher alkane production ${ }^{39,40}$. Furthermore, balancing the alkane biosynthesis, fatty alcohol accumulation and fatty acid metabolism and engineering the electron transfer system significantly improved alkane production to $1.31 \mathrm{~g} \mathrm{l}^{-1}$ in $E$. coli under fed-batch fermentation, the highest reported titre in engineered microbes ${ }^{41}$.

1-Alkenes (olefins) can be produced directly from FFAs through expression of the fatty acid peroxygenase Ole $_{\mathrm{IE}}$ in a fatty acidoverproducing E. coli strain, leading to production of $97 \mathrm{mg} \mathrm{l}^{-1}$ long odd-chain 1-alkenes ${ }^{42}$ with a chain length of C13-C17. Recently, a non-heme iron oxidase was identified to enable medium-chain 1-alkene production in $E$. coli with a titre of $5 \mathrm{mg} \mathrm{l}^{-1}$ (ref. ${ }^{31}$ ), while desaturase-like UndB was shown to be more efficient for production of 1 -alkenes $\left(60 \mathrm{mg} \mathrm{l}^{-1}\right)$ with a broad product spectrum of C7-C17 in E. coli ${ }^{30}$.

$S$. cerevisiae is widely used as a cell factory due to its robustness toward harsh industrial conditions. The first demonstration of alkane production by yeast was a reconstruction of very long-chain alkane (mainly C29 nonacosane) biosynthesis from Arabidopsis thaliana (A. thaliana ${ }^{29}$. More recently, the cyanobacteria alkane pathway was successfully reconstructed in S. cerevisiae, following the identification of the main competing enzyme, aldehyde dehydrogenase Hfd1. Deletion of $h f d 1$ in combination with expression of E. coli ferredoxin and ferredoxin-NADP reductase allowed the 
Table 1 | Microbial production of hydrocarbons

\begin{tabular}{|c|c|c|c|c|c|c|}
\hline Hydrocarbon products & Chain length & Host & Cultivation condition ${ }^{\mathrm{a}}$ & Titre & Yield & Ref. \\
\hline \multicolumn{7}{|l|}{ Isoprenoid derived } \\
\hline Isoprene & $\mathrm{C} 5$ & E. coli & MM + glucose, fed-batch & $60 \mathrm{~g} \mathrm{l}^{-1}$ & 0.110 g per g & 14 \\
\hline Isoprene & C5 & S. cerevisiae & MM + sucrose, fed-batch & $2.5 \mathrm{~g} \mathrm{I}^{-1}$ & 0.011 g per gb & 15 \\
\hline Isoprene & $\mathrm{C} 5$ & S. elongatus & $\mathrm{BG}-11$ medium $+\mathrm{CO}_{2}$ flow & $1.3 \mathrm{~g} \mathrm{I}^{-1}$ & $65 \%$ fixed carbon & 16 \\
\hline Limonene & C10 & E. coli & EZ rich media + glucose, shake flask & $605 \mathrm{mg} \mathrm{l}^{-1}$ & $0.061 \mathrm{~g}$ per $\mathrm{g}$ & 21 \\
\hline Limonene & $\mathrm{C} 10$ & Y. lipolytica & $\mathrm{CM}+$ glucose, shake flask & $24 \mathrm{mg} \mathrm{l}^{-1}$ & $N C^{c}$ & 22 \\
\hline Limonene & C10 & Synechococcus sp & Solid $\mathrm{A}+$ media with $\mathrm{N}$ depletion & $4.5 \mathrm{mg} \mathrm{l}^{-1}$ & $N C^{d}$ & 17 \\
\hline Sabinene & C10 & E. coli & MM + glycerol, fed-batch & $2.7 \mathrm{~g} \mathrm{l}^{-1}$ & $3.5 \times 10^{-3} \mathrm{~g}$ per $g$ & 20 \\
\hline Farnesene & C15 & S. cerevisiae & MM + glucose, fed-batch & $130 \mathrm{~g} \mathrm{I}^{-1}$ & $0.173 \mathrm{~g}$ per g & 24 \\
\hline Bisabolene & C15 & E. coli & EZ rich media + glucose, shake flask & $1.15 \mathrm{~g} \mathrm{I}^{-1}$ & $0.015 \mathrm{~g}$ per $\mathrm{g}$ & 21 \\
\hline Bisabolene & C15 & S. cerevisiae & $\mathrm{CM}+$ galactose + glucose, shake flask & $1.0 \mathrm{~g} \mathrm{I}^{-1}$ & 0.05 g per g & 26 \\
\hline \multicolumn{7}{|l|}{ Fatty acid derived } \\
\hline Long-chain alkanes & $\mathrm{C} 13-\mathrm{C} 17$ & E. coli & MM + glucose, shake flask & $0.30 \mathrm{~g} \mathrm{I}^{-1}$ & $0.010 \mathrm{~g}$ per $\mathrm{g}$ & 28 \\
\hline Long-chain alkanes & $\mathrm{C} 15, \mathrm{C} 17$ & E. coli & MM + glycerol, fed-batch & $1.31 \mathrm{~g} \mathrm{|}^{-1}$ & $0.011 \mathrm{~g}$ per g & 41 \\
\hline Short-chain alkanes & C9-C13 & E. coli & MM + glucose, shake flask & $0.58 \mathrm{~g} \mathrm{l}^{-1}$ & $N C^{c}$ & 34 \\
\hline Short-chain alkanes & $\mathrm{C} 3, \mathrm{C} 4, \mathrm{C} 5$ & E. coli & LB + glycerol, shake flask & $1.3-4.3 \mathrm{mg} \mathrm{l}^{-1}$ & $N C^{c}$ & 36 \\
\hline Propane & $\mathrm{C} 3$ & E. coli & MM + glucose, batch & $32 \mathrm{mg} \mathrm{I}^{-1}$ & $4.3 \times 10^{-4} \mathrm{~g}$ per $\mathrm{g}$ & 35 \\
\hline Long-chain alkanes & $\mathrm{C} 13-\mathrm{C} 17$ & S. cerevisiae & MM + glucose, shake flask & $3.6 \mathrm{mg} \mathrm{l}^{-1}$ & $1.2 \times 10^{-4}$ g per $g$ & 45 \\
\hline Long-chain alkane & $\mathrm{C} 13-\mathrm{C} 17$ & Y. lipolytica & MM + glucose, shake flask & $23 \mathrm{mg} \mathrm{l}^{-1}$ & $3.9 \times 10^{-4}$ g per $g$ & 52 \\
\hline Long-chain 1-alkenes & $\mathrm{C} 13-\mathrm{C} 17$ & E. coli & MM + glucose, shake flask & $97 \mathrm{mg} \mathrm{l}^{-1}$ & $3.2 \times 10^{-3} \mathrm{~g}$ per $\mathrm{g}$ & 42 \\
\hline Long-chain 1-alkenes & C11-C19 & S. cerevisiae & MM + glucose, shake flask & $35.3 \mathrm{mg} \mathrm{l}^{-1}$ & $1.8 \times 10^{-3} \mathrm{~g}$ per $g$ & 47 \\
\hline \multicolumn{7}{|l|}{ PKS derived } \\
\hline Pentadecaheptaene & C15 & E. coli & MM + glucose, fed-batch & $140 \mathrm{mg} \mathrm{l}^{-1}$ & 0.003 g per g & 55 \\
\hline
\end{tabular}

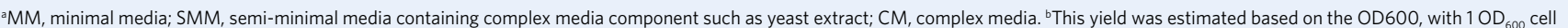
density is $0.6 \mathrm{~g} \mathrm{DCW}^{-1}$ and a biomass yield of $0.5 \mathrm{~g} \mathrm{DCW}$ per g glucose. ${ }^{\mathrm{C}}$ Not calculated due to containing complex media component such as yeast extract. ${ }^{\mathrm{d}} \mathrm{Not}$ calculated due to a lack of information on consumption of carbon sources such as glucose.

production of alkanes at $0.1 \mathrm{mg} \mathrm{l}^{-1}\left(\right.$ ref. $\left.^{43}\right)$. Construction of a FFAderived alkane pathway resulted in almost 300\% improved alkane production compared to the fatty-CoA derived pathway ${ }^{44}$. Deletion of the main ALR/ADH adh5 and enhancement of the expression of $\mathrm{ADO}$ further increased alkane production by $70 \%$, again pointing to this step as having major flux control ${ }^{44}$. As an alternative strategy, the alkane pathway was targeted to the peroxisome, an organelle responsible for FFA degradation and free of ALR/ADHs, which improved alkane production by $100 \%$ with decreased accumulation of by-product fatty alcohols. Engineering peroxisome biogenesis further enhanced alkane production by threefold $\left(3.6 \mathrm{mg} \mathrm{l}^{-1}\right)^{45}$. $\mathrm{OleT}_{\mathrm{IE}}$ catalysed 1-alkene production is low in S. cerevisiae, that is, $3.7 \mathrm{mg} \mathrm{l}^{-1} 1$-alkenes under fed-batch fermentation ${ }^{46}$ compared with $^{-1}$ $97 \mathrm{mg} \mathrm{l}^{-1}$ in E. coli, but production of olefins could also be improved by targeting the pathway to the peroxisomes ${ }^{45}$. Furthermore, dynamic expression of a desaturase-like UndB and exporter longchain fatty acid transport protein 1 (FATP1) in a FFA overproducing $S$. cerevisiae resulted in the production of $35.3 \mathrm{mg} \mathrm{l}^{-1} 1$-alkenes with more than $80 \%$ being secreted, which represented a tenfold improvement compared with earlier reported 1-alkene production by $S$. cerevisiae ${ }^{47}$. Recently, the yeast type-I FAS domain, which previously was considered to be rigidly organized, has been engineered for biosynthesis of short-chain fatty acids and their derived hydrocarbons $^{48-50}$. This opened a door to explore FAS I novel functions for production of new hydrocarbons with different properties.

Expression of a soybean lipoxygenase (Gmlox1) in the oleaginous yeast Yarrowia lipolytica (Y. lipolytica) transformed inoleic acid into tridecadieonoic acid and pentane at a titre of $5 \mathrm{mg} \mathrm{l}^{-1}$ (ref. ${ }^{51}$ ). However, this lipoxygenase-based pathway has high substrate speci- ficity towards linoleic acid, a rare fatty acid species, and would produce equal molar of by-product tridecadieonoic acid, which limits its future industrial application. Recently, reconstruction and optimization of alkane biosynthetic pathways in Y. lipolytica enabled alkane production of $23 \mathrm{mg} \mathrm{l}^{-1}$ (ref. ${ }^{52}$ ). The relatively low alkane titre in yeast compared with bacteria (Table 1) might be attributed to the unsuitable environment for ADO activity in the yeast cytosol. ADOs are iron and ferredoxin-dependent, and iron-sulfur clusters are assembled in the mitochondria of yeast and the yeast iron-sulfur clusters may also be incompatible with $\mathrm{ADO}$ of bacterial origin.

Cyanobacteria can produce alkanes directly from $\mathrm{CO}_{2}$ and sunlight ${ }^{53}$, but the low productivity limits industrial application. Many cyanobacteria naturally produce polyhydroxybutyrates $(\mathrm{PHB})$ that are also derived from acetyl-CoA, and by expressing alkane pathway genes carbon flux was redirected to acyl-ACP by blocking PHB biosynthesis, resulting in 8.3-fold improved alkane production $\left(26 \mathrm{mg} \mathrm{l}^{-1}\right)^{54}$.

Hydrocarbon production from polyketide biosynthetic pathways. Polyketides represent a family of natural products that possess a wide variety of pharmacological or biological activities, and the type-I polyketide synthase (PKS1) is very similar to FAS with multiple domains, which can be used for reductive biosynthesis of hydrocarbons. A polyketide synthase Ols from Synechococcus has been verified to be involved in biosynthesis of 1-alkene 1-nonadecene $^{33}$. Recently, an iterative type-I polyketide synthase (PKS) $\mathrm{SgcE}$, which is involved in enediyne core biosynthesis, has been engineered for production of pentadecaheptaene. Optimizing the expression of $\mathrm{SgcE}$ and its cognate thioesterase (TE) SgcE10 in 
E. coli resulted in high pentadecaheptaene production, while fedbatch fermentation followed by chemical hydrogenation resulted in $140 \mathrm{mg} \mathrm{l}^{-1}$ pentadecane ${ }^{55}$. Furthermore, hybrid PKSs have been constructed from different naturally occurring PKS and expressed in $E$. coli, which enabled the production of a variety of $\alpha$-olefins such as propene, pentene and 1-hexane $\mathrm{e}^{56}$. These results clearly show the potential of engineering PKS for production of hydrocarbons with different chemical structures, by exploiting the high flexibility of PKS modules ${ }^{57}$.

The challenge of hydrocarbon toxicity and possible solutions. Hydrocarbons, especially many terpenes, cause toxicity stress to microbial cells ${ }^{58}$, which limits the improvement of titres and productivities. Transporter and tolerance engineering has successfully improved the robustness of microbial cell factories; however, cellular energy is required to relieve this stress and thus lower yields are obtained $^{59}$. In contrast to the focus on bioactivity in pharmaceutical use, for hydrocarbons to be used as biofuels the thermodynamic and physicochemical properties are more important and these must be comparable to current fuels. Thus, identifying non-toxic or lowtoxicity hydrocarbons, with similar properties to current petroleum-derived fuels, would be a feasible approach to realize high production without product inhibition (Fig. 3). Since terpene structures are controlled by terpene synthases, construction of a library of terpene synthase genes in microbial cells followed by growthcoupled screening could enable identification of non- or low-toxic molecules for further pathway and robustness engineering. With construction of multiple pathways that can operate in parallel, it is possible to create cell factories that produce a terpene mix with similar thermodynamic and physicochemical properties to petroleumderived fuels. For example, it was found that a farnesene-overlay in a limonene producing cell culture for in situ product extraction relieved limonene toxicity significantly, and a $10 \%(\mathrm{v} / \mathrm{v} \%)$ blend of limonene in farnesene had similar physicochemical properties to Jet-A specifications ${ }^{60}$. Thus, precise metabolic engineering would enable cell factories to produce a mix of limonene and farnesene at a ratio of 10:90 (by volume) that can be used as Jet-A fuels with less toxicity compared to single limonene producing cells, which is beneficial for higher biosynthetic efficiency (Fig. 3).

\section{Engineering utilization of single-carbon feedstocks}

Single-carbon feedstocks for hydrocarbon production have the advantage of high natural abundance (for example $\mathrm{CO}_{2}$ and methane) or current large-scale manufacturing (for example methanol, which is produced from natural gas or coal). The use of $\mathrm{CO}_{2}$ as a carbon source could also directly reduce GHG emissions, while methane, a major component of natural gas and also a GHG, can additionally be used as a feedstock for bio-manufacturing of chemicals and biofuels ${ }^{61}$. Methanol, which is produced in very large amounts from natural gas or coal, also represents a usable carbon source for microbial fermentations ${ }^{62}$.

$\mathrm{CO}_{2}$ itself can be used as the main carbon source for biomass and energy storage through natural photosynthesis, but the rate of natural photosynthesis is low and therefore efficiency is not sufficient for commercial production. Furthermore, it does not result in chemicals that can be used as fuels. Compared to biomass-derived sugar biomanufacturing, it is more challenging to produce hydrocarbons (for example, farnesene) from $\mathrm{CO}_{2}$, since it requires extensive chemical reduction and thus needs large amounts of reducing power to remove oxygen atoms and supply the hydrogen atoms (Fig. 4). Most attempts to improve biological $\mathrm{CO}_{2}$ fixation have focused on engineering the photosynthesis efficiency in natural systems ${ }^{63,64}$. However, the slow growth and difficulty with engineering plants and autotrophic organisms limits the progress in improving the native $\mathrm{CO}_{2}$ fixation efficiency for production of specific chemicals. Alternative efforts have focused on engineering $\mathrm{CO}_{2}$ fixation systems into cell factories like E. coli and S. cerevisiae ${ }^{65,66}$. Recently, a chimeric functional Calvin-Benson-Bassham cycle was introduced into E. coli, which enabled the biosynthesis of sugars and other major biomass constituents with the energy module for ATP and reducing power supply ${ }^{67}$. This study achieved a fully functional non-native carbon assimilation cycle to synthesize pathway intermediates and products from $\mathrm{CO}_{2}$ in a heterologous host, which represents an important advance toward the goal of engineering autotrophy into a model microorganism. In another study, a nonnatural $\mathrm{CO}_{2}$ fixation cycle, the 'crotonyl-CoA/ethylmalonyl-CoA/ hydroxybutyryl-CoA' (CETCH) cycle, was more energy efficient and achieved unprecedented in vitro $\mathrm{CO}_{2}$ fixation efficiencies ${ }^{68}$. The energy harvest efficiency in photosynthesis is, however, relatively low, and therefore alternative approaches have been used such as combining inorganic semiconductors for more efficient energy harvesting and using the non-photosynthetic bacterium Moorella thermoacetica to capture electrons from the semiconductors and fix $\mathrm{CO}_{2}$, enabling production of acetic acid from $\mathrm{CO}_{2}$ (ref. ${ }^{69}$ ). A similar concept allows for use of electrons from electricity, for example, generated by wind, solar or hydro, for conversion of $\mathrm{CO}_{2}$ to chemicals that can be used as fuels, for example, isobutanol ${ }^{70}$. Artificial photosynthesis could also play an important role in developing efficient and elegant processes for solar-hydrocarbon conversion through $\mathrm{CO}_{2}$ fixation ${ }^{71}$.

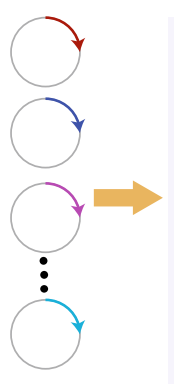

Library construction

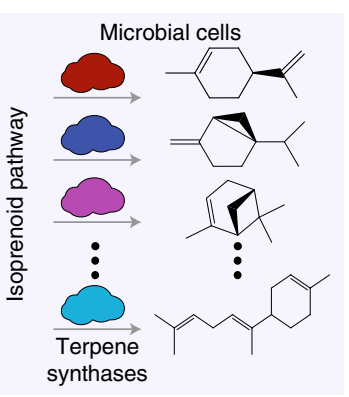

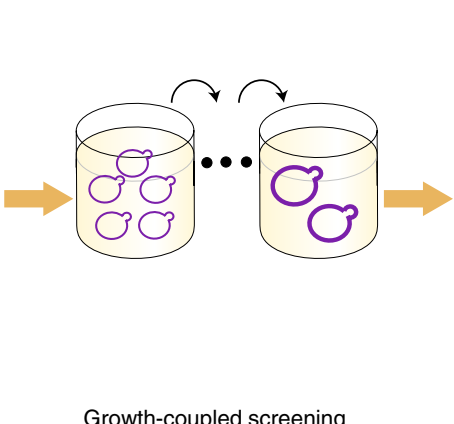

Growth-coupled screening
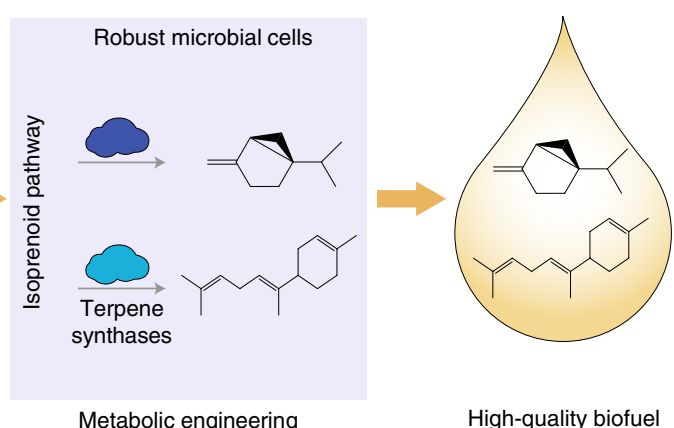

High-quality biofuel

Fig. 3 | Construction of microbial cell factories for overproduction of terpene-based biofuels with relieved toxicity. Identification of non- or low-toxic terpene molecules is helpful to improve the microbial production of terpenes for biofuel purposes, since many terpenes have considerable toxicity, which limits their production level. Cloning a diversity of terpene synthase genes in a microbial cell, with engineered efficient isoprenoid biosynthetic pathways, provides an enzyme library for screening of low-toxic terpene producing enzymes. Growth-coupled screening can enrich the cells containing low-toxic terpene synthases. Precise metabolic engineering can create robust microbial cells that overproduce terpene mixes at specific ratios, which have low toxicity to the microbes and similar physicochemical properties to current fuels. 
a

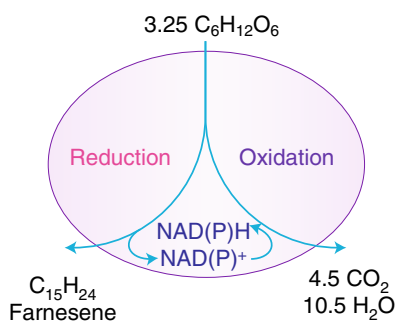

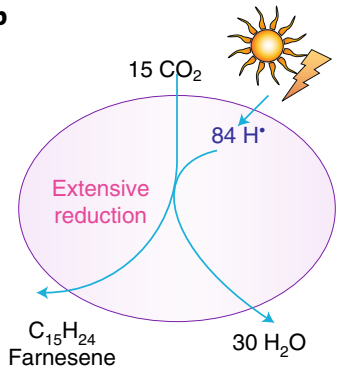

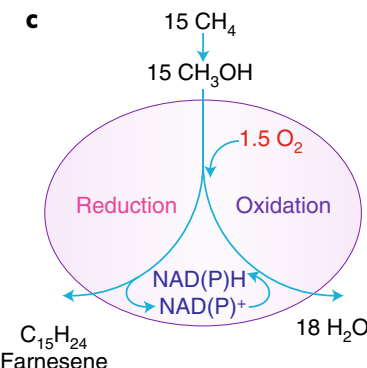

Fig. 4 | Stoichiometric biosynthesis of farnesene from hexose, $\mathrm{CO}_{2}$ or methanol. a, Sugar (for example, hexose) based farnesene biosynthesis can be considered as two processes: the reduction process for farnesene biosynthesis and the deoxygenation process for oxygen removal. The oxidation process generates the reducing power for the reduction process. $\mathbf{b}, \mathrm{CO}_{2}$-based hydrocarbon biosynthesis is an extensive reduction process, which needs many electrons $\mathrm{H}^{\bullet}$ to remove oxygen and supply hydrogen atoms. $\mathbf{c}$, Methane and methanol are already more reduced than $\mathrm{CO}_{2}$ or sugars, resulting in more facile biosynthesis of farnesene.

Methane is a main component of natural gas and accounts for another main source of GHG emissions besides $\mathrm{CO}_{2}$. Thus, exploring methane as a feedstock for biomanufacturing ${ }^{61}$ could relieve substrate stress and GHG emissions. Methane catabolism is initiated by oxidized activation via methanol. It should be mentioned that methane/methanol have higher hydrogen/oxygen ratios than sugar and $\mathrm{CO}_{2}$, which make them thermodynamically well suited for hydrocarbon biosynthesis (Fig. 4). Thus, converting methane and methanol to hydrocarbon-based biofuels could contribute to the production of transportation fuels in addition to their use in other sectors ${ }^{72}$. With the rise in shale gas production there has been increased interest in using methanol as a carbon source for bioprocessing. There are two different approaches for engineering microorganisms for conversion of methanol to hydrocarbons: (1) engineering methylotrophy into non-methylotrophic hosts such as E. coli or S. cerevisiae, which has been successfully exploited for the overproduction of a variety of products (top-down pipeline) ( $^{73}$; (2) construction and optimization of heterologous downstream biosynthesis pathways for overproduction in a methylotrophic host (bottom-up pipeline) ${ }^{62}$ (Fig. 5). Establishing synthetic methylotrophy (approach 1), that is, reconstruction of the methanol utilization pathway in a clean chassis host, can give insight into the methanol catabolism mechanisms, which can help to improve the methanol conversion efficiency in natural methylotrophic hosts. For example, construction and optimization of a methanol utilization pathway from methylotrophic bacteria in E. coli enabled the incorporation of methanol into central metabolites ${ }^{74}$ and even specific chemicals such as naringenin ${ }^{75}$. Unfortunately, the synthetic strain could not grow on methanol as the sole carbon source, and the methanol catabolism efficiency is still too low for industrial application. However, engineering of a methylotroph pathway into a non-methylotrophic chassis gives important insights into methanol catabolism. Alternatively, engineering of the methylotrophic bacterium Methylobacterium extorquens enabled de novo synthesis of the sesquiterpene $\alpha$-humulene $\left(1.65 \mathrm{~g} \mathrm{l}^{-1}\right.$ ) from methanol (Fig. 5b) ${ }^{76}$. Through further optimization of the methanol utilization and isoprenoid pathways, production of mevalonate reached $2.7 \mathrm{~g} \mathrm{l}^{-1}$ with a yield of $0.08 \mathrm{~g}$ per $\mathrm{g}$ methanol ${ }^{77}$. The methylotrophic yeast Pichia pastoris has also been engineered for production of lycopene ${ }^{78}$ and nootkatone ${ }^{79}$. These results show the potential in engineering methylotrophic microorganisms for production of hydrocarbons from methanol, which could be used for conversion of natural gas or coal to hydrocarbons (Fig. 1). This approach could pave the road for conversion of coal to microbial-derived hydrocarbons that represents a cleaner route to energy supply than burning coal directly.

It is more challenging to use methane directly because methane activation (that is, partial oxidation) is extremely inefficient, and this
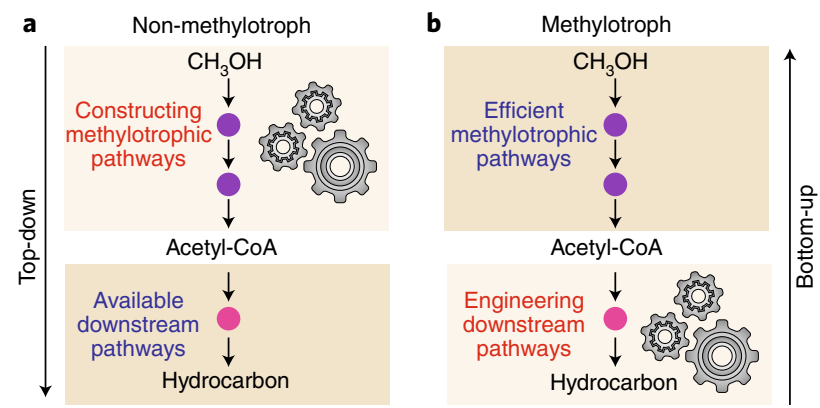

Fig. 5 | Engineering cell factories for hydrocarbon biosynthesis from methanol. There are two approaches in construction of microbial cell factories to convert methanol to hydrocarbon biosynthesis. a, Methylotrophic pathways must be engineered to enable methanol utilization in non-methylotrophic microorganisms such as $E$. coli or $S$. cerevisiae. Well-developed molecular techniques and an extensive library of knowledge in model microbes enables rapid metabolic engineering for production of specific compounds such as isoprenoids and fatty acidderived hydrocarbons from intermediate acetyl-CoA. b, This approach requires engineering of downstream hydrocarbon biosynthesis pathways in methylotrophic organisms, which have relatively high methanol catabolism. Reconstruction and optimization of downstream tailoring pathways redirect the metabolic flux toward hydrocarbon biosynthesis from methanol. However, the limited availability of genetic tools and biochemical knowledge makes it more difficult to perform pathway and cellular engineering. The arrow width indicates the strength of metabolic flux; the purple and pink dots represent the intermediates of methyltrophic pathways and downstream pathways, respectively.

poses a considerable upstream problem in the biological production of fuels or chemicals from methane ${ }^{80,81}$. There are two main biological methane oxidation routes: aerobic methane oxidation catalysed by methane monooxygenase, and the much less efficient anaerobic oxidation mainly catalysed by methyl-coenzyme $\mathrm{M}$ reductase. The current methane bioconversion primarily focuses on engineering methanotrophs that use the methane oxidation route for production of chemicals and biofuels ${ }^{82}$. Methanotrophic bacteria have been engineered for production of several biofuel molecules (isobutanol, butanol, fatty alcohols and fatty acid methyl esters) ${ }^{83}$ and farnesene ${ }^{84}$ by using methane as a carbon source, but in all cases with a very low titre. There are fewer reports on using anaerobic methane oxidation, but the archaeal methanogen Methanosarcina acetivorans has been engineered to grow on methane and anaerobically convert it 
into acetate ${ }^{85}$, which is assumed to be more energy efficient than the aerobic methane oxidation. So far there has been no successful report on engineering methanotrophy into model organisms such as E. coli or S. cerevisiae, and only the soluble domain of the $\beta$-subunit methane oxygenase has been expressed in $E$. coli with extremely low activity ${ }^{86}$, clearly demonstrating the challenge in constructing a non-natural methanotrophic host for methane conversion. Besides the challenge of improving the efficiency of methane activation, development of methane-based biomanufacturing faces two other major challenges: the first challenge is the low solubility of methane and oxygen that limits the gas-to-liquid (GTL) mass transfer and impacts the productivity of the fermentation process. Thus, it is necessary to improve the mass transfer of oxygen and methane and recycle the residual gas with new bioreactor design, which has been widely explored in the chemical industry such as slurry reactor design. GTL mass transfer efficiency can be enhanced by increasing the gas solubility via pressurizing the bioreactor or by increasing the GTL mass-transfer coefficient $\left(k_{\mathrm{L}} \mathrm{a}\right)$ via improving the bioreactor design. As an example, a bubble column bioreactor was optimized for anaerobic $\mathrm{CO}_{2}$ fixation with the acetogenic bacterium Moorella thermoacetica ${ }^{87}$, which enabled efficient acetic acid production from $\mathrm{CO}_{2}$ at a titre of $31 \mathrm{~g} \mathrm{l}^{-1}$, and a productivity of $0.55 \mathrm{~g} \mathrm{l}^{-1} \mathrm{~h}^{-1}$. A second challenge is improving the robustness of the methanotrophic hosts to ensure that they have high growth rates and are resistant to industrial conditions. Methanotrophic microbes live at a low density in natural conditions, which are not suitable for industrial processes, and it is therefore necessary to engineer these organisms to have higher growth rate and improved tolerance against harsh industrial conditions to ensure high productivities.

\section{Challenges and solutions}

As mentioned earlier, there are two major barriers in developing bio-based production of hydrocarbons. The first is the realization of an efficient and robust cell factory ${ }^{11}$, and the development of an industrially relevant cell factory is a costly process, typically US\$50-100 million and involves several different steps ${ }^{13}$ (Fig. 6). The second is in developing efficient integration of microbial conversion of sugars to hydrocarbons with a process for biomass hydrolysis, used to produce the sugars.

Proof-of-concept cell factory. Cell factory development commences with a proof-of-concept, initiated by identifying a hydrocarbon of interest and existence of a naturally occurring biosynthetic pathway. While natural producers can occasionally be found, for example, alkane-producing cyanobacteria ${ }^{28}$, these species often preclude further optimization and eventual industrial use due to very low productivity or poor robustness towards harsh industrial conditions. Alternatively, a strategy can be designed where the pathway is expressed in a heterologous host with more beneficial characteristics and that is genetically tractable, for example, the transfer of A. thaliana genes to $S$. cerevisiae for alkane production ${ }^{29}$. The discovery of efficient enzymes from nature is challenging and could benefit from high-throughput screening of enzymes from a wide range of backgrounds.

Improving titre, rate and yield. While a proof-of-concept demonstrates feasibility of hydrocarbon production, it is merely the onset for extensive improvement towards an industrial microbial cell factory. Three key metrics for a successful bioprocess are titre, rate and yield (TRY) (Figs. 6 and 7). Many academic studies only report final titre as a measure of performance, as illustrated in our review of different engineered strains above. However, due to the relatively low cost of hydrocarbons, the most important metrics to optimize are arguably rate and yield: high rate (or productivity) requires less capital investment while high yields ensure efficient utilization of the feedstock, which may account for up to $70 \%$ of total production costs (the case for bioethanol production) but may be lower if biomass is used as feedstock. Titre, cannot, however, be disregarded, as a dilute mixture of hydrocarbons increases costs in downstream processing. Current yields (Table 1) leave plenty of room for improvement, as the theoretical maximum yield of many biofuels is around $0.3 \mathrm{~g}$ per g glucose (Fig. 7). Even at maximum theoretical yield, economic evaluation of biofuel production indicates the need for subsidies to compete directly with oil. Assuming a FA ethyl ester production rate of $7.5 \mathrm{~g} \mathrm{l}^{-1} \mathrm{~h}^{-1}$ and an annual production up to 75,000 tons, the sugar price should be below US $\$ 0.07$ for a biodiesel price of US $\$ 0.60$ per litre ${ }^{11}$, but sugar is currently priced above US $\$ 0.20 \mathrm{~kg}^{-1}$. A mature lignocellulose process may be able to produce sugar at around US $\$ 0.08 \mathrm{~kg}^{-1}$ (ref. ${ }^{88}$ ), while alternative sources can potentially provide carbons more cheaply, possibly allowing cost-competitive biofuel production in the future.

The TRY metrics can be improved by metabolic engineering of the cell factory, for example, expressing heterologous genes or modulating the expression of autologous genes ${ }^{13}$. This engineering is, however, troubled by the rigidity of microbial metabolism: millions of years of evolution have shaped microbial metabolism to efficiently produce the building blocks and energy that microbes require for their growth. Redirecting carbon and energy flux towards a desired hydrocarbon can therefore be challenging, and thus much interest exists in developing platform cell factories that are optimized for high-level production of specific precursors ${ }^{89}$. For hydrocarbons in particular, platform strains optimized for acetyl-CoA production are of interest, as many hydrocarbons have acetyl-CoA as a precursor $^{90}$. Another consideration is the use of a host that naturally has a considerable carbon flux towards production of precursors or similar molecules as the hydrocarbon of interest ${ }^{91}$. Oleaginous yeast such as Y. lipolytica are capable of accumulating large amounts of lipids that can be converted to preferred hydrocarbons ${ }^{52}$. In addition to optimizing biosynthetic pathways, catabolic pathways require attention, for example, for a biorefinery where biomass is used as feedstock, cell factories should be capable of efficiently metabolizing both C5- and C6-sugars. Therefore, already in an early stage it should be decided what feedstock will be used and this should be taken into consideration when choosing the cell factory.

Improving TRY metrics typically involves iterative rounds of the 'Design-Build-Test-Learn (DBTL)' cycle $^{13}$ (Fig. 6). During the design (D) phase, the researcher has an objective in mind, such as increased productivity of a hydrocarbon. These objectives can be obtained via various strategies, such as changing co-factor preferences of pathway enzymes, removing competing pathways, or screening of efficient alternative biosynthetic pathways or enzymes. Designing new strategies can be aided by computational analysis, where genome-scale metabolic models (GEMs) in particular have been shown to be helpful ${ }^{92}$. GEMs can be used to in silico test different engineering strategies, prioritizing designs predicted to have the most beneficial effects ${ }^{93}$.

Once a new design has been enumerated, implementation takes place during the build (B) phase. This challenging phase is not only aided using platform strains, but also advances in gene synthesis and CRISPR-Cas9 technology for genome editing have significantly shortened the build phase. Moreover, high-throughput robotics is now capable of building many strains in a short period.

Newly built cell factories are subsequently tested (T), not only focusing on the design objective, or even merely quantifying the TRY metrics, but also including study of the strain physiology and regulatory response using omics analysis ${ }^{94}$. Such a systems approach allows broader questions to be answered: if a competing pathway is blocked, or a new pathway is introduced, how does the cell factory redirect its fluxes and respond by altering gene expression? The microbe's response can be measured on various levels, using techniques such as metabolomics, proteomics and transcriptomics. This information results in new knowledge about the cell factory and represents the 


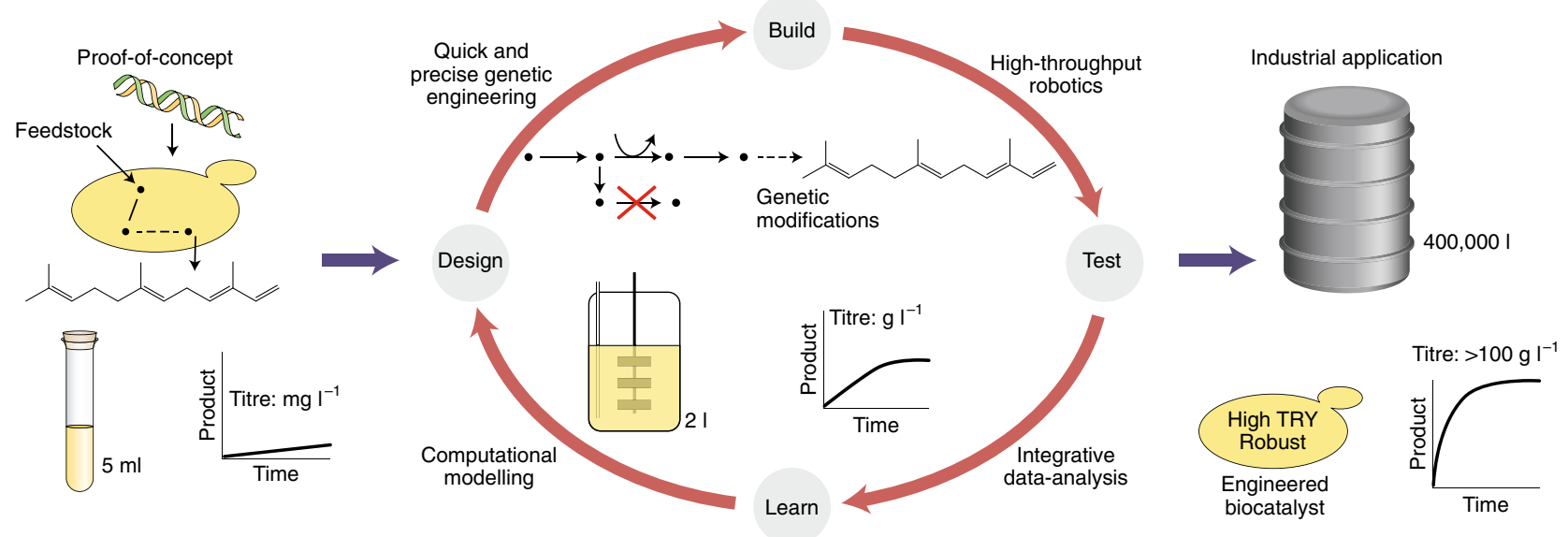

Fig. 6 | Development of a microbial cell factory for hydrocarbon production from raw materials. From a proof-of-concept stage, where preliminary pathway engineering results in low titres on a small scale, the titre, rate and yield are improved through multiple rounds of the design-build-test-learn (DBTL)-cycle. Each part of this cycle can be aided by various techniques, and innovations in these areas (for example, CRISPR-Cas9 and genetic engineering) will speed-up and improve the efficiency of the DBTL-cycle. Further genetic engineering of the cell factory by removing competing pathways and optimizing co-factor recycling increases titres while cultures are performed on a larger scale. The final step towards industrial application is the scale-up and improvement of robustness of the cell factory that now has high titre, rate and yield on a very large scale.

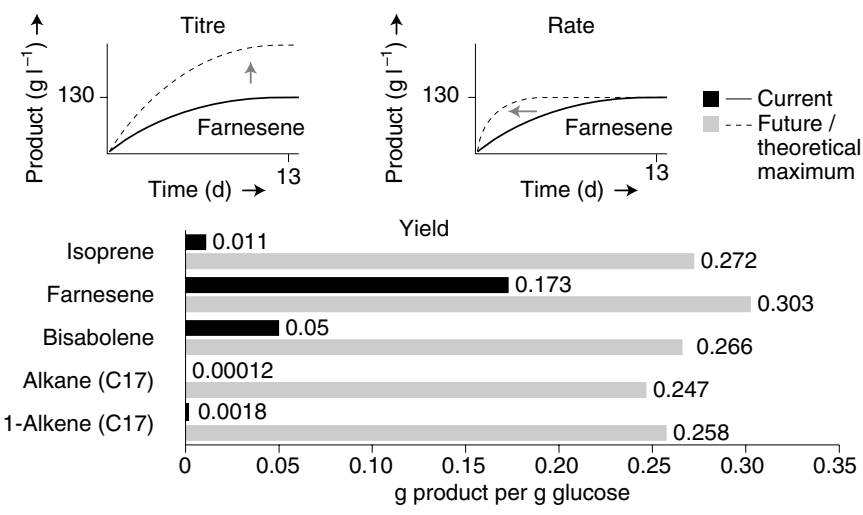

Fig. 7 | Room for improvement of TRY metrics. Industrial application of cell factories requires improvements on the final concentration (titre) of the product, the rate at which the product is formed, and the yield of product relative to the consumed nutrient source. Shown are current metrics with S. cerevisiae as cell factory, taken from Table 1. Current titre and rate are given for farnesene as an example, while maximum theoretical yields are calculated using a genome-scale model (See Methods).

learn (L) phase, which can be used to guide the next design round. The L phase is of particular importance when a design fails, that is, the design objective was not met, as through understanding the failure new knowledge about the cell factory is acquired.

The DBTL cycle represents a stepwise improvement towards producing an industrial cell factory, a process that is expensive and takes many years as it involves many rounds of the DBTL cycle.

Robustness and scale-up. A desired property of cell factories important to consider is their ability to tolerate harsh industrial conditions, for example, high osmolarity, hypoxia and in particular high product concentrations. As part of the scale-up from laboratory-scale to industrial-scale fermentations, the cell factory's robustness can be improved through adaptive laboratory evolution where the microbe is evolved to withstand harsh conditions ${ }^{95}$. Due to random mutations naturally occurring during the cell cycle, prolonged exposure to harsh conditions eventually results in beneficial mutations that confer an advantage for the cell. This approach has been used to identify how S. cerevisiae can be engineered to tolerant high temperatures ${ }^{96}$ and low $\mathrm{pH}^{97}$, while in both cases mutations in ergosterol biosynthesis conferred tolerance by altering membrane sterol compositions. Another detrimental source of inhibition is contamination of the feedstock with inhibiting compounds. This is of particular concern with biomass as it requires harsh pre-treatment to release the fermentable sugars. To this end, E. coli has been evolved to withstand increasing levels of ionic liquids that are used in lignocellulosic hydrolysis, but the underlying mechanism was not elucidated ${ }^{98}$.

Moving to the use of biomass as a feedstock. Today, primarily corn and sugar cane are being used as feedstock for production of microbial-derived biofuels, but there have been several initiatives to use lignocellulose from biomass, for example, corn stover, wood or bagasse, as an alternative feedstock. Due to its abundance, biomass is considered as an ideal bio-refinery feedstock for production of hydrocarbon-based biofuels, and clearly it will be necessary to eventually integrate a microbial fermentation process for conversion of sugars to hydrocarbons with a process for deconstruction of biomass to fermentable sugars. This deconstruction process generally starts with a pre-treatment process followed by enzymatic hydrolysis. Various pre-treatment processes have been developed, that is, physical, chemical, biological or a combination of these ${ }^{99}$, and some of these have even been implemented for large-scale processing of biomass in connection with second-generation ethanol production. One example is the Beta Renewables plant in Crescentino, Italy, that uses rice and wheat straws as biomass feedstock to produce about 40,000 tons of ethanol annually. In the pre-treatment stage biomass breaks into pulp at the microscopic level resulting in separation into lignin, cellulose and hemicellulose. The different fractions can then be further processed, and using enzymatic degradation combined with fermentation, so-called simultaneous saccharification and fermentation, the production costs has been reduced significantly. A similar process has been implemented by SEKAB in Sweden, in this case for processing of wood chips and other residues from the Swedish forest industry. Also, in Brazil second-generation bioethanol production has been established, for example, by Raizen that developed a plant in a joint venture with Canadian Iogen, and once fully operational it will be producing $>10$ million gallons of 
ethanol annually. Even though these new plants are not yet running at full capacity, their operation will eventually result in further refinement and optimization of the processes, and this will pave the way for integrating these biomass processing plants with production of biofuels other than ethanol.

\section{Outlook}

Bio-based production of hydrocarbons provides several attractive opportunities for the energy sector: production of molecules with improved properties; sustainable production from renewable feedstock such as biomass and $\mathrm{CO}_{2}$; reduction in GHG emissions; and reduction in particle emission. However, commercial bio-based production of hydrocarbons faces three main barriers: high costs of developing a cell factory (>US\$50 million); difficulties in obtaining cost-competitive production; and high sensitivity to volatile oil prices. Overcoming these challenges calls for new scientific discoveries, new technology developments and engineering designs. Concerning single-carbon feedstock conversion, the efficiency of methane activation needs to be improved by orders of magnitude, and this requires discovery of novel efficient enzymes and further optimization of the metabolic network.

Since biological and chemical processes have different pros and cons, combining their advantages could help to develop an economically viable process for hydrocarbon production ${ }^{100}$. For example, low efficiency enzymes limit alkane production from fatty acids, and one may therefore consider producing fatty acids from biomass followed by conversion of these to hydrocarbons through chemical processes like HEFA.

In summary, current advances in molecular genetics, systems biology and synthetic biology can be used for enzyme discovery, pathway exploration, biosystems design and construction, which will advance microbial cell factory development, and hereby make it faster and cheaper to develop efficient bioprocesses for production of hydrocarbons to be used as drop-in biofuels. In particular, when these production processes are integrated with processes for biomass deconstruction currently being implemented and optimized in connection with the development of second-generation ethanol production it will become possible to have low-cost production at volumes of significance in terms of contributing to reduced GHG and particle emissions from trucks and airplanes.

\section{Methods}

Calculating theoretical maximum yields. From Table 1, hydrocarbons produced by $S$. cerevisiae were selected to calculate theoretical maximum yields using a genome-scale model (GEM). The consensus GEM Yeast 7.6, including modifications ${ }^{101}$, was used to represent the stoichiometry of the S. cerevisiae metabolic network, with the following hydrocarbon-specific additions, where compartmental localization of metabolites is indicated inside square brackets ( $\mathrm{c}$ is cytosol, $\mathrm{p}$ is peroxisome and $\mathrm{m}$ is mitochondria). Reactions involving the null sign $\phi$ are sink reactions, whose products are not balanced during flux balance analysis.

Isoprene. As specified previously ${ }^{15}$, a mitochondrial isoprene synthase reaction was added to the GEM, together with an exchange reaction assuming passive transport:

prenyl diphosphate $[\mathrm{m}] \rightarrow$ isoprene $[\mathrm{m}]+\operatorname{diphosphate}[\mathrm{m}]$

$$
\text { isoprene }[\mathrm{m}] \rightarrow \phi
$$

The mevalonate pathway was localized to the mitochondrion (reactions r_0558, r_0667, r_0735, r_0736, r_0737, r_0738, r_0739, r_0904).

Farnesene. As specified previously ${ }^{24}$, phosphoketolase, phosphotransacetylase, acetaldehyde dehydrogenase (acetylating), NADH-HMG reductase and farnesene synthase reactions were added to the GEM, together with an exchange reaction assuming passive transport:

$$
\begin{aligned}
& \text { D - xylulose } 5 \text { - phosphate }[\mathrm{c}]+\text { phosphate }[\mathrm{c}] \rightarrow \text { glyceraldehyde } \\
& 3 \text { - phosphate }[\mathrm{c}]+\text { acetyl }- \text { phosphate }[\mathrm{c}]+\mathrm{H}_{2} \mathrm{O}[\mathrm{c}]
\end{aligned}
$$

acetyl - phosphate $[\mathrm{c}]+$ coenzyme $\mathrm{A}[\mathrm{c}] \rightarrow \operatorname{acetyl}-\mathrm{CoA}[\mathrm{c}]+$ phosphate $[\mathrm{c}]$

$$
\begin{gathered}
\text { acetaldehyde }[\mathrm{c}]+\text { coenzyme } \mathrm{A}[\mathrm{c}]+\mathrm{NAD}[\mathrm{c}] \\
\rightarrow \text { acetyl }-\mathrm{CoA}[\mathrm{c}]+\mathrm{NADH}[\mathrm{c}]+\mathrm{H}^{+}[\mathrm{c}]
\end{gathered}
$$

$$
\begin{gathered}
\text { 3- hydroxy }-3-\text { methylglutaryl }-\mathrm{CoA}[\mathrm{c}]+2 \mathrm{H}^{+}[\mathrm{c}]+2 \mathrm{NADH}[\mathrm{c}] \\
\rightarrow(\mathrm{R})-\text { mevalonate }[\mathrm{c}]+\text { coenzyme } \mathrm{A}[\mathrm{c}]+2 \mathrm{NAD}[\mathrm{c}]
\end{gathered}
$$

farnesyl diphosphate $[c] \rightarrow$ farnesene $[c]+$ diphosphate $[c]$

$$
\text { farnesene }[c] \rightarrow \phi
$$

Bisabolene. As specified previously ${ }^{26}$, a cytosolic bisabolene synthase reaction was added to the GEM, together with an exchange reaction assuming passive transport:

$$
\text { farnesyl diphosphate }[c] \rightarrow \text { bisabolene }[c]+\text { diphosphate }[c]
$$

bisabolene $[c] \rightarrow \phi$

Long-chain alkanes. Heptadecane was selected as representative long-chain alkane, and as specified previously ${ }^{45}$, peroxisomal carboxylic acid reductase and aldehydedeformylating oxygenase (simplified by removing ferredoxin cycle) reactions were added to the GEM, together with an exchange reaction assuming passive transport, and a formate diffusion reaction:

$$
\begin{aligned}
& \text { stearate }[\mathrm{p}]+\mathrm{NADPH}[\mathrm{p}]+\operatorname{ATP}[\mathrm{p}] \rightarrow \operatorname{octadecanal}[\mathrm{p}] \\
& +\mathrm{NADP}(+)[\mathrm{p}]+\operatorname{AMP}[\mathrm{p}]+\operatorname{diphosphate}[\mathrm{p}]+\mathrm{H}_{2} \mathrm{O}[\mathrm{p}]
\end{aligned}
$$

$$
\operatorname{octadecanal}[\mathrm{p}]+\operatorname{oxygen}[\mathrm{p}]+2 \mathrm{NADPH}[\mathrm{p}]+2 \mathrm{H}^{+}[\mathrm{p}]
$$$$
\rightarrow \text { heptadecane }[\mathrm{p}]+\text { formate }[\mathrm{p}]+2 \mathrm{NADP}(+)[\mathrm{p}]+\mathrm{H}_{2} \mathrm{O}[\mathrm{p}]
$$

$$
\text { heptadecane }[\mathrm{p}] \rightarrow \phi
$$

$$
\text { formate }[\mathrm{p}] \rightarrow \text { formate }[\mathrm{c}]
$$

Long-chain 1-alkenes. 1-Heptadecane was selected as representative longchain 1-alkene, and as specified previously ${ }^{46}$, a cytochrome $\mathrm{P} 450$ fatty acid decarboxylase was added to the GEM, together with an exchange reaction assuming passive transport, and for simplification a reaction generating hydrogen peroxide:

$$
\begin{aligned}
& \text { stearate }[\mathrm{c}]+\text { hydrogen peroxide }[\mathrm{c}]+\mathrm{H}^{+}[\mathrm{c}] \\
& \rightarrow 1 \text {-heptadecane }[\mathrm{c}]+\text { carbon dioxide }[\mathrm{c}]+2 \mathrm{H}_{2} \mathrm{O}[\mathrm{c}] \\
& 1 \text {-heptadecane }[\mathrm{c}] \rightarrow \phi \\
& 2 \mathrm{H}_{2} \mathrm{O}[\mathrm{c}]+\text { oxygen }[\mathrm{c}] \rightarrow 2 \text { hydrogen peroxide }[\mathrm{c}]
\end{aligned}
$$

Flux balance analysis. Non-growth associated maintenance was set to 0 , while the sole restricting nutrient was glucose with $-1 \mathrm{mmol}$ per g DCW per h. Flux balance analysis was performed with RAVEN Toolbox ${ }^{102}$, setting production of the hydrocarbon of interest as objective function, resulting in the maximum theoretical yields in comparison to reported yields (Fig. 7).

Received: 3 June 2017; Accepted: 5 June 2018; Published online: 30 July 2018

\section{References}

1. Use of Energy in the United States Explained: Energy Use for Transportation (US Energy Information and Administration, 2016); https://go.nature.com/2sH2qsJ

2. Liao, J. C., Mi, L., Pontrelli, S. \& Luo, S. Fuelling the future: microbial engineering for the production of sustainable biofuels. Nat. Rev. Microbiol. 14, 288-304 (2016). 
3. Lynd, L. R. The grand challenge of cellulosic biofuels. Nat. Biotechnol. 35, 912-915 (2017).

4. ICAO Environmental Report 2016: Aviation and Environmental Outlook 38-65 (ICAO, 2016).

5. Moore, R. H. et al. Biofuel blending reduces particle emissions from aircraft engines at cruise conditions. Nature 543, 411-415 (2017)

6. Kocar, G. \& Civas, N. An overview of biofuels from energy crops: Current status and future prospects. Renew. Sust. Energ. Rev. 28, 900-916 (2013).

7. Peralta-Yahya, P. P., Zhang, F., del Cardayre, S. B. \& Keasling, J. D. Microbial engineering for the production of advanced biofuels. Nature 488, 320-328 (2012).

8. Lee, S. Y., Kim, H. M. \& Cheon, S. Metabolic engineering for the production of hydrocarbon fuels. Curr. Opin. Biotechnol. 33, 15-22 (2015).

9. Fellet, M. Aviation industry hopes to cut emissions with jet biofuel. Chem. Eng. News 94, 16-18 (2016).

10. Gevo's alcohol-to-jet fuel meets approved ASTM standard. Biomass Magazine http://biomassmagazine.com/articles/13078/gevoundefinedsalcohol-to-jet-fuel-meets-approved-astm-standard (2016).

11. Caspeta, L. \& Nielsen, J. Economic and environmental impacts of microbial biodiesel. Nat. Biotechnol. 31, 789-793 (2013).

12. Technology Roadmap: Biofuels for Transport (International Energy Agency, 2011).

13. Nielsen, J. \& Keasling, J. D. Engineering cellular metabolism. Cell 164, 1185-1197 (2016).

This review comprehensively discusses the challenges and strategies in constructing microbial cell factories.

14. Whited, G. M. et al. Development of a gas-phase bioprocess for isoprenemonomer production using metabolic pathway engineering. Ind. Biotechnol. 6, 152-163 (2010).

15. Lv, X. M. et al. Dual regulation of cytoplasmic and mitochondrial acetyl-CoA utilization for improved isoprene production in Saccharomyces cerevisiae. Nat. Commun. 7, 12851 (2016)

16. Gao, X. et al. Engineering the methylerythritol phosphate pathway in cyanobacteria for photosynthetic isoprene production from $\mathrm{CO}_{2}$. Energy Environ. Sci. 9, 1400-1411 (2016).

17. Davies, F. K., Work, V. H., Beliaev, A. S. \& Posewitz, M. C. Engineering limonene and bisabolene production in wild type and a glycogen-deficient mutant of Synechococcus sp. PCC 7002. Front. Bioeng. Biotechnol. 2, 21 (2014).

18. Zebec, Z. et al. Towards synthesis of monoterpenes and derivatives using synthetic biology. Curr. Opin. Chem. Biol. 34, 37-43 (2016).

19. Tashiro, M. et al. Bacterial production of pinene by a laboratory-evolved pinene-synthase. ACS Synth. Biol. 5, 1011-1120 (2016).

20. Zhang, $\mathrm{H}$. et al. Microbial production of sabinene-a new terpene-based precursor of advanced biofuel. Microb. Cell Fact. 13, 20 (2014).

21. Alonso-Gutierrez, J. et al. Principal component analysis of proteomics (PCAP) as a tool to direct metabolic engineering. Metab. Eng. 28, 123-133 (2015).

22. Cao, X. et al. Metabolic engineering of oleaginous yeast Yarrowia lipolytica for limonene overproduction. Biotechnol. Biofuels 9, 214 (2016).

23. Ignea, C., Pontini, M., Maffei, M. E., Makris, A. M. \& Kampranis, S. C. Engineering monoterpene production in yeast using a synthetic dominant negative geranyl diphosphate synthase. ACS Synth. Biol. 3, 298-306 (2014).

24. Meadows, A. L. et al. Rewriting yeast central carbon metabolism for industrial isoprenoid production. Nature 537, 694-697 (2016)

This work rewired the yeast central metabolism by using four non-native metabolic reactions for improved cytosolic precursor acetyl-CoA supply, reduced ATP requirement, reduced $\mathrm{CO}_{2}$ emissions and improved pathway redox balance, which had a $25 \%$ higher farnesene yield on glucose ( $130 \mathrm{~g} \mathrm{l}^{-1}, 0.173 \mathrm{~g}$ per $\mathrm{g}$ glucose) and $75 \%$ less oxygen consumption.

25. Paddon, C. J. et al. High-level semi-synthetic production of the potent antimalarial artemisinin. Nature 496, 528-532 (2013).

26. Peralta-Yahya, P. P. et al. Identification and microbial production of a terpene-based advanced biofuel. Nat. Commun. 2, 483 (2011).

27. Pfleger, B. F., Gossing, M. \& Nielsen, J. Metabolic engineering strategies for microbial synthesis of oleochemicals. Metab. Eng. 29, 1-11 (2015).

28. Schirmer, A., Rude, M. A., Li, X., Popova, E. \& del Cardayre, S. B. Microbial biosynthesis of alkanes. Science 329, 559-562 (2010).

29. Bernard, A. et al. Reconstitution of plant alkane biosynthesis in yeast demonstrates that Arabidopsis ECERIFERUM1 and ECERIFERUM3 are core components of a very-long-chain alkane synthesis complex. Plant Cell 24, 3106-3118 (2012).

30. Rui, Z., Harris, N. C., Zhu, X. J., Huang, W. \& Zhang, W. J. Discovery of a family of desaturase-like enzymes for 1-alkene biosynthesis. ACS Catal. 5, 7091-7094 (2015)

This study discovered efficient membrane-bound desaturase-like enzymes for long-chain 1-alkene biosynthesis from fatty acids.

31. Rui, Z. et al. Microbial biosynthesis of medium-chain 1-alkenes by a nonheme iron oxidase. Proc. Natl Acad. Sci. USA 111, 18237-18242 (2014).
32. Rude, M. A. et al. Terminal olefin (1-alkene) biosynthesis by a novel P450 fatty acid decarboxylase from Jeotgalicoccus species. Appl. Environ. Microb. 77, 1718-1727 (2011).

33. Mendez-Perez, D., Begemann, M. B. \& Pfleger, B. F. Modular synthaseencoding gene involved in alpha-olefin biosynthesis in Synechococcus sp. strain PCC 7002. Appl. Environ. Microb. 77, 4264-4267 (2011).

34. Choi, Y. J. \& Lee, S. Y. Microbial production of short-chain alkanes. Nature 502, 571-574 (2013).

35. Kallio, P., Pasztor, A., Thiel, K., Akhtar, M. K. \& Jones, P. R. An engineered pathway for the biosynthesis of renewable propane. Nat. Commun. 5, 4731 (2014).

36. Sheppard, M. J., Kunjapur, A. M. \& Prather, K. L. Modular and selective biosynthesis of gasoline-range alkanes. Metab. Eng. 33, 28-40 (2016).

37. Andre, C., Kim, S. W., Yu, X. H. \& Shanklin, J. Fusing catalase to an alkaneproducing enzyme maintains enzymatic activity by converting the inhibitory byproduct $\mathrm{H}_{2} \mathrm{O}_{2}$ to the cosubstrate $\mathrm{O}_{2}$. Proc. Natl Acad. Sci. USA 110, 3191-3196 (2013)

38. Rodriguez, G. M. \& Atsumi, S. Toward aldehyde and alkane production by removing aldehyde reductase activity in Escherichia coli. Metab. Eng. 25, 227-237 (2014).

39. Rahmana, Z. et al. Enhanced production of n-alkanes in Escherichia coli by spatial organization of biosynthetic pathway enzymes. J. Biotechnol. 192, 187-191 (2014).

40. Sachdeva, G., Garg, A., Godding, D., Way, J. C. \& Silver, P. A. In vivo co-localization of enzymes on RNA scaffolds increases metabolic production in a geometrically dependent manner. Nucleic Acids Res. 42, 9493-9503 (2014).

41. Cao, Y. X. et al. Heterologous biosynthesis and manipulation of alkanes in Escherichia coli. Metab. Eng. 38, 19-28 (2016).

This work used a multi-modular optimization approach to alkane production in $E$. coli by balancing the fatty aldehyde node and engineering fatty acid metabolism and electron transfer system, resulting in $1.31 \mathrm{~g} \mathrm{l}^{-1}$ alkane production in fed-batch fermentation by using glycerol as carbon source.

42. Liu, Y. et al. Hydrogen peroxide-independent production of alphaalkenes by OleTJE P450 fatty acid decarboxylase. Biotechnol. Biofuels 7, 28 (2014).

43. Buijs, N. A., Zhou, Y. J., Siewers, V. \& Nielsen, J. Long-chain alkane production by the yeast Saccharomyces cerevisiae. Biotechnol. Bioeng. 112, 1275-1279 (2015).

44. Zhou, Y. J. et al. Production of fatty acid-derived oleochemicals and biofuels by synthetic yeast cell factories. Nat. Commun. 7, 11709 (2016).

45. Zhou, Y. J. et al. Harnessing yeast peroxisomes for biosynthesis of fatty-acid-derived biofuels and chemicals with relieved side-pathway competition. J. Am. Chem. Soc. 138, 15368-15377 (2016).

46. Chen, B., Lee, D. Y. \& Chang, M. W. Combinatorial metabolic engineering of Saccharomyces cerevisiae for terminal alkene production. Metab. Eng. 31 53-61 (2015).

47. Zhou, Y. J., Hu, Y., Zhu, Z., Siewers, V. \& Nielsen, J. Engineering 1-alkene biosynthesis and secretion by dynamic regulation in yeast. ACS Synth. Biol. 7, 584-590 (2018)

48. Zhu, Z. et al. Expanding the product portfolio of fungal type I fatty acid synthases. Nat. Chem. Biol. 13, 360-362 (2017).

49. Gajewski, J. et al. Engineering fatty acid synthases for directed polyketide production. Nat. Chem. Biol. 13, 363-365 (2017).

50. Zhu, Z. et al. Enabling the synthesis of medium chain alkanes and 1-alkenes in yeast. Metab. Eng. 44, 81-88 (2017).

51. Blazeck, J., Liu, L., Knight, R. \& Alper, H. S. Heterologous production of pentane in the oleaginous yeast Yarrowia lipolytica. J. Biotechnol. 165 184-194 (2013).

52. Xu, P., Qiao, K. J., Ahn, W. S. \& Stephanopoulos, G. Engineering Yarrowia lipolytica as a platform for synthesis of drop-in transportation fuels and oleochemicals. Proc. Natl Acad. Sci. USA 113, 10848-10853 (2016).

53. Angermayr, S. A., Gorchs Rovira, A. \& Hellingwerf, K. J. Metabolic engineering of cyanobacteria for the synthesis of commodity products. Trends Biotechnol. 33, 352-361 (2015).

54. Wang, W., Liu, X. \& Lu, X. Engineering cyanobacteria to improve photosynthetic production of alka(e)nes. Biotechnol. Biofuels. 6, 69 (2013).

55. Liu, Q. et al. Engineering an iterative polyketide pathway in Escherichia coli results in single-form alkene and alkane overproduction. Metab. Eng. 28, 82-90 (2015).

This paper shows that the polyketide pathway can be engineered for biosynthesis of alkenes.

56. Fortman, J. L., Katz, L., Steen, E. J. \& Keasling, J. D. Producing alpha-olefins using polyketide synthases. US patent 2016/0068827 A1 (2016).

57. Yuzawa, S., Keasling, J. D. \& Katz, L. Bio-based production of fuels and industrial chemicals by repurposing antibiotic-producing type I modular polyketide synthases: opportunities and challenges. J. Antibiot. 70, 378-385 (2017). 
58. Sikkema, J., de Bont, J. A. \& Poolman, B. Mechanisms of membrane toxicity of hydrocarbons. Microbiol. Rev. 59, 201-222 (1995).

59. Gong, Z., Nielsen, J. \& Zhou, Y. J. Engineering robustness of microbial cell factories. Biotechnol. J. 12, 201700014 (2017).

60. Brennan, T. C. R., Turner, C. D., Kromer, J. O. \& Nielsen, L. K. Alleviating monoterpene toxicity using a two-phase extractive fermentation for the bioproduction of jet fuel mixtures in Saccharomyces cerevisiae. Biotechnol. Bioeng. 109, 2513-2522 (2012).

61. Clomburg, J. M., Crumbley, A. M. \& Gonzalez, R. Industrial biomanufacturing: The future of chemical production. Science 355, aag0804 (2017).

This review compares the biomanufacturing and chemical process in regard to economies of unit number, investment scale and financial risk, and proposes that biomanufacturing could play an important role in conversion of single-carbon feedstocks to chemicals and biofuels with rapid adaptation to new and changing markets.

62. Schrader, J. et al. Methanol-based industrial biotechnology: current status and future perspectives of methylotrophic bacteria. Trends Biotechnol. 27, 107-115 (2009).

63. Shih, P. M., Zarzycki, J., Niyogi, K. K. \& Kerfeld, C. A. Introduction of a synthetic $\mathrm{CO}_{2}$-fixing photorespiratory bypass into a cyanobacterium. J. Biol. Chem. 289, 9493-9500 (2014).

64. Lin, M. T., Occhialini, A., Andralojc, P. J., Parry, M. A. J. \& Hanson, M. R. A faster Rubisco with potential to increase photosynthesis in crops. Nature 513, 547-550 (2014)

65. Gong, F. et al. Quantitative analysis of an engineered CO2-fixing Escherichia coli reveals great potential of heterotrophic $\mathrm{CO} 2$ fixation. Biotechnol. Biofuels 8, 86 (2015).

66. Guadalupe-Medina, V. et al. Carbon dioxide fixation by Calvin-Cycle enzymes improves ethanol yield in yeast. Biotechnol. Biofuels 6, 125 (2013).

67. Antonovsky, N. et al. Sugar Synthesis from CO2 in Escherichia coli. Cell 166, 115-125 (2016).

A non-native Calvin-Benson-Bassham cycle was functionally constructed in $E$. coli and enabled biomass synthesis from $\mathrm{CO}_{2}$ directly with the supply of ATP and reducing power.

68. Schwander, T., Schada von Borzyskowski, L., Burgener, S., Cortina, N. S. \& Erb, T. J. A synthetic pathway for the fixation of carbon dioxide in vitro. Science 354, 900-904 (2016).

69. Sakimoto, K. K., Wong, A. B. \& Yang, P. Self-photosensitization of nonphotosynthetic bacteria for solar-to-chemical production. Science 351, 74-77 (2016).

A biological-inorganic hybrid, combining inorganic semiconductors and non-photosynthetic bacterium, was developed for highly efficient light harvesting and $\mathrm{CO}_{2}$ fixation toward acetate production.

70. $\mathrm{Li}, \mathrm{H}$. et al. Integrated electromicrobial conversion of $\mathrm{CO}_{2}$ to higher alcohols. Science 335, 1596 (2012).

71. Romero, E., Novoderezhkin, V. I. \& van Grondelle, R. Quantum design of photosynthesis for bio-inspired solar-energy conversion. Nature 543, 355-365 (2017).

72. Haynes, C. A. \& Gonzalez, R. Rethinking biological activation of methane and conversion to liquid fuels. Nat. Chem. Biol. 10, 331-339 (2014).

73. Whitaker, W. B., Sandoval, N. R., Bennett, R. K., Fast, A. G. \& Papoutsakis, E. T. Synthetic methylotrophy: engineering the production of biofuels and chemicals based on the biology of aerobic methanol utilization. Curr. Opin. Biotechnol. 33, 165-175 (2015).

74. Muller, J. E. et al. Engineering Escherichia coli for methanol conversion. Metab. Eng. 28, 190-201 (2015).

A heterologous methanol utilization pathway was constructed in $E$. coli, which enabled up to $40 \%$ incorporation of methanol into central metabolites.

75. Whitaker, W. B. et al. Engineering the biological conversion of methanol to specialty chemicals in Escherichia coli. Metab. Eng. 39, 49-59 (2017).

76. Sonntag, F. et al. Engineering Methylobacterium extorquens for de novo synthesis of the sesquiterpenoid alpha-humulene from methanol. Metab. Eng. 32, 82-94 (2015).

77. Liang, W. F. et al. Biosensor-assisted transcriptional regulator engineering for Methylobacterium extorquens AM1 to improve mevalonate synthesis by increasing the acetyl-CoA supply. Metab. Eng. 39, 159-168 (2017).

78. Bhataya, A., Schmidt-Dannert, C. \& Lee, P. C. Metabolic engineering of Pichia pastoris X-33 for lycopene production. Process Biochem. 44, 1095-1102 (2009).

79. Wriessnegger, T. et al. Production of the sesquiterpenoid (+)-nootkatone by metabolic engineering of Pichia pastoris. Metab. Eng. 24, 18-29 (2014).

80. Lawton, T. J. \& Rosenzweig, A. C. Methane-oxidizing enzymes: An upstream problem in biological gas-to-liquids conversion. J. Am. Chem. Soc. 138, 9327-9340 (2016).

81. Conrado, R. J. \& Gonzalez, R. Envisioning the bioconversion of methane to liquid fuels. Science 343, 621-623 (2014)

82. Kalyuzhnaya, M. G., Puri, A. W. \& Lidstrom, M. E. Metabolic engineering in methanotrophic bacteria. Metab. Eng. 29, 142-152 (2015).
83. Coleman, W. J. et al. Biological conversion of multi-carbon compounds from methane. US patent 20160160243A1 (2016).

84. Intrexon's industrial products division achieves bioconversion of methane to farnesene. Intrexon https://investors.dna.com/2014-06-30-IntrexonsIndustrial-Products-Division-Achieves-Bioconversion-of-Methane-toFarnesene (2014).

85. Soo, V. W. et al. Reversing methanogenesis to capture methane for liquid biofuel precursors. Microb. Cell Fact. 15, 11 (2016).

86. Balasubramanian, R. et al. Oxidation of methane by a biological dicopper centre. Nature 465, 115-119 (2010).

87. $\mathrm{Hu}$, P., Rismani-Yazdi, H. \& Stephanopoulos, G. Anaerobic $\mathrm{CO}_{2}$ fixation by the acetogenic bacterium Moorella thermoacetica. AICHE J. 59, 3176-3183 (2013)

88. Lynd, L. R. et al. How biotech can transform biofuels. Nat. Biotechnol. 26 169-172 (2008).

89. Nielsen, J. Yeast cell factories on the horizon. Science 349 , 1050-1051 (2015).

90. Krivoruchko, A., Zhang, Y., Siewers, V., Chen, Y. \& Nielsen, J. Microbial acetyl-CoA metabolism and metabolic engineering. Metab. Eng. 28, 28-42 (2015).

91. Levering, J., Broddrick, J. \& Zengler, K. Engineering of oleaginous organisms for lipid production. Curr. Opin. Biotechnol. 36, 32-39 (2015).

92. Lee, S. Y. \& Kim, H. U. Systems strategies for developing industrial microbial strains. Nat. Biotechnol. 33, 1061-1072 (2015).

93. Kerkhoven, E. J., Lahtvee, P. J. \& Nielsen, J. Applications of computational modeling in metabolic engineering of yeast. FEMS Yeast Res. 15, 1-13 (2015).

94. Brunk, E. et al. Characterizing strain variation in engineered E. coli using a multi-omics-based workflow. Cell Syst. 2, 335-346 (2016).

A multi-omics workflow was applied to elucidate engineered cell factories and identify potential engineering targets for improved production of interesting metabolites.

95. Dragosits, M. \& Mattanovich, D. Adaptive laboratory evolution - principles and applications for biotechnology. Microb. Cell Fact. 12, 64 (2013).

96. Caspeta, L. et al. Altered sterol composition renders yeast thermotolerant. Science 346, 75-78 (2014)

97. Fletcher, E. et al. Evolutionary engineering reveals divergent paths when yeast is adapted to different acidic environments. Metab. Eng. 39, 19-28 (2017).

98. Mi, L. et al. Efficient production of free fatty acids from ionic liquid-based acid- or enzyme-catalyzed bamboo hydrolysate. J. Ind. Microbiol. Biotechnol. 44, 419-430 (2017).

99. Agbor, V. B., Cicek, N., Sparling, R., Berlin, A. \& Levin, D. B. Biomass pretreatment: fundamentals toward application. Biotechnol. Adv. 29, 675-685 (2011)

100. Anbarasan, P. et al. Integration of chemical catalysis with extractive fermentation to produce fuels. Nature 491, 235-239 (2012). This paper shows how chemical and biological processes work coordinatively for synthesizing hydrocarbon biofuels from renewable sources.

101. Sanchez, B. J. et al. Improving the phenotype predictions of a yeast genomescale metabolic model by incorporating enzymatic constraints. Mol. Syst. Biol. 13, 935 (2017).

102. Wang, H. et al. RAVEN 2.0: a versatile platform for metabolic network reconstruction and a case study on Streptomyces coelicolor. Preprint at https://doi.org/10.1101/321067 (2018).

\section{Acknowledgements}

The authors acknowledge funding from National Natural Science Foundation of Chin (grant no. 31700082) and DMTO research grant from Dalian Institute of Chemicals Physics, CAS (grant no. DICP DMTO201701) (to Y.J.Z.); the Novo Nordisk Foundation, the Knut and Alice Wallenberg Foundation, the US Department of Energy, Office of Science, Office of Biological and Environmental Research, Genomic Science program (Award number DE-SC0008744) and Horizon2020 via the CHASSY project (grant no. 720824) (to J.N.) and Åforsk Foundation (to E.J.K.).

\section{Competing interests}

The authors declare no competing interests.

\section{Additional information}

Reprints and permissions information is available at www.nature.com/reprints. Correspondence should be addressed to J.N

Publisher's note: Springer Nature remains neutral with regard to jurisdictional claims in published maps and institutional affiliations. 